\title{
Immunohistochemical Differentiation between Reactive and Malignant Mesothelial Proliferations in Pleural Effusion
}

\author{
MOHEBAT H. GOUDA, M.D.*; MOHAMMED ELMAHDY, M.D.** and GEHAN M. ELOSEILY, M.D.*** \\ The Departments of Pathology*, Chest**, Faculty of Medicine, Benha University, Egypt and Department of Pathology***, \\ Faculty of Medicine, Assiut University, Egypt \& Almarefa University, KSA
}

\begin{abstract}
Background: The differentiation between benign and malignant mesothelial cells in pleural effusion in some cases can be a challenge. In the current study, we investigated the value of immunohistochemistry (IHC) in making that differentiation.
\end{abstract}

Aim of Study: This study aims to examine the value of IHC expression of desmin, EMA, GLUT-1, p53, Ki67, and BAP1 in discrimination between benign and malignant mesothelial proliferation in pleural effusions and compare their results regarding sensitivity and specificity.

Material and Methods: Pleural fluids from 30 cases diagnosed as malignant meothelioma (MM) epitheloid type and 20 cases diagnosed as reactive mesothelial hyperplasia $(\mathrm{RMH})$ were selected, and stained with immunohistochemical stains included BAP-1, desmin, epithelial membrane antigen (EMA), glucose-transport protein 1 (GLUTÅ]1), Ki67, and $\mathrm{p}^{53}$

Results: BAP-1 was negative in 5\% ( 1 of 20$)$ cases of reactive $\mathrm{MH}$ and in $63.3 \%$ (19 of 30 ) of MM cases $(p<.005)$. GLUT $\AA$ ] 1 was positive in $15 \%$ (3 of 20 ) of benign and $70 \%$ (21 of 30$)$ of malignant cases $(p<.005)$. Desmin was positive in $80 \%$ ( 16 of 20 ) cases of reactive $\mathrm{MH}$ and in $10 \%$ (3 of 30$)$ of MM cases $(p<.001)$. EMA was positive in $10 \%$ ( 2 of 20$)$ of benign and $96.7 \%$ (29 of 30) of malignant cases $(p<.001)$. P53 showed strong nuclear positivity in 5\% (1 of 20) of benign and $53.3 \%$ (16 of 30$)$ of malignant cases $(p<.001)$. Ki67 showed strong nuclear positivity in $>40 \%$ of mesothelial cells in $10 \%$ ( 2 of 20 ) of benign and $16.7 \%$ ( 5 of 30 ) of malignant cases $(p=0.40)$. EMA negativity and desmin positivity were found in $75 \%$ (15 of 20) of reactive $\mathrm{MH}$ cases and 3.3\% (one of 30) of MM cases. EMA positivity and desmin negativity were found in $5 \%$ ( 1 of 20 ) of reactive $\mathrm{MH}$ cases and $90 \%$ (27 of 30) of MM cases $(p<.001)$. Positivity for both of Desmin and BAP-1 was detected in $80 \%$ (16 of 20) of RMH cases. The combination of Desmin and BAP-1 negativity was detected in $60 \%$ (16 of 30$)$ of MM cases ( $p$-value $p<.001)$.

Conclusions: Cases showed positivity for EMA and negativity for desmin strongly favors malignant mesothelioma. On the contrary, cases showed negative EMA and positive

Correspondence to: Dr. Mohebat H. Gouda, The Department of Pathology, Faculty of Medicine, Benha University, Egypt desmin strongly favors Reactive mesothelial hyperplasia. also the combination of Desmin and Bap-1 postivity favors diagnosis of RMH, and the combination of Desmin and BAP 1 negativity favors the diagnosis of MM. Similarly, cases showed strong membranous expression of GLUT-1 and/or strong nuclear expression of $\mathrm{p} 53$ strongly favors diagnosis of malignant mesothelioma. Proliferative index showed detected by Ki67 showed no significant difference between reactive and malignant cases.

Key Words: BAP-1 - P53 - Ki67 - Desmin - EMA - GLUT1 - Reactive mesothelial hyperplasia $(R M H)-$ Malignant mesothelioma (MM) - Immunohistochemistry (IHC).

\section{Introduction}

MALIGNANT mesothelioma is a highly aggressive neoplasm with a worse outcome, usually linked to asbestos. The neoplasm arises from the mesothelial cells that line the serous cavities, especially the pleura. Mesothelioma has a poor prognosis $[1,2]$. Survival rates are low with a median survival of 4 to 14 months. The cases are usually diagnosed late, and the available therapeutic regimens are limited. The incidence of malignant mesothelioma has been increasing all over the world since the mid 20th century [3]

Malignant mesothelioma (MM) has many different morphologic types which commonly difficult to be differentiated from reactive proliferation of mesothelial cells or tumors of nonmesothelial origin arising form serous membranes [4]. So it is difficult to diagnose a case as malignant mesotheliom with great confidence, especially if the biopsy is small on using routine light microscopy alone [5]. For that cause, additional techniques for diagnosis as histochemistry, EM, and IHC, usually needed help the pathologistto have a more confident diagnosis and support him to identify the (1) Mesothelial origin and (2) Malignant nature of the lesion [6] . 
The identification of the nature of proliferated mesothelial cells benign or malignant is essential for the patient treatment, but the pathologist even experts find such differentiation, in some cases, so difficult $[\mathbf{7 , 8}]$. Stromal invasion is considered the clue for diagnosing proilfertaed mesothelial cells as malignant in tissue biopsy, but in pleural effusion it is not applicable $[\mathbf{9 , 1 0}$. The cellular morphological criteria that used to define cells as malignant are pleomorphism, macronucleoli, large cellular aggregates, papillary-like tissue fragments, and cell-in-cell engulfment. These are important criteria, but of limited value in cytologic effusion as they may be present in cases with RMH. RMH may be associated with variable degrees of cytological atypi, conversely some cases of MM may be associated with bland cytological features [11,12]

BAP1 gene encodes BRCA1-associated protein 1 (BAP1) which acts as nuclear hydrolase included in many cellular processes, as chromatin remodeling. BAP1 acts as a true tumor suppressor gene $[13,14]$. Families with increased incidence of MM, have shown the presence of germline BAP1 mutations. Recently, this led to the identification of the BAP1 tumor predisposition syndrome that is inherited in an $\mathrm{AD}$ manner and is characterised by uveal melanoma, mesothelioma, cutaneous melanocytic lesions, renal cell carcinoma, basal cell carcinoma, and may be associated with intrahepatic cholangiocarcinoma $[\mathbf{1 5}, \mathbf{1 6}]$. Similarly, Sporadic BAP-1 was also detected in some neoplasms as uveal melanoma, MM, and cutaneous melanocytic tumors $[17,18]$.

Malignant cells supply their energy needs through increased glucose consumption, producing large quantities of lactic acid via glycolysis. Glucose transporters (GLUTs) and monocarboxylate transporters (MCTs) [19]. It can usually be detected in erythrocytes, the blood-brain barrier, and the placenta but rarely in other organs. It is commonly up-regulated in human malignancies to mediate glucose influx and lactic acid efflux, respectively [20].

P53 is a 53-kDa nuclear protein. It is encoded by tumor suppressor gene p53 which lies on short arm of chromosome 17. P53 has many roles in the cell as transcription, cell cycle regulation, repair of DNA, and induce apoptosis of cells with damaged DNA to keep the genetic stability [21]. P53 gene deletions or mutations are common event in many human neoplasms (60\%) that causing tumor growth. The product of mutated p53 gene has a longer half life than the normal protein and more stable, so this mutated protein is easily identified by IHC. Thus cells of malignant tumors not benign tumors have high levels of such mutated proteine [22].

$\mathrm{Ki} 67$ is a nuclear protein that regulate cell proliferation, can be identified by monoclonal antibody MIB- 1 . its expression is nuclear in the active cell phase $(\mathrm{G} 1, \mathrm{~S}, \mathrm{G} 2, \mathrm{M})$ not in the resting phase (G0) [23]. Detection of Ki67 is used to detect the growth fraction (the number of cells in cell cycle) of normal, reactive, and neoplastic tissue. The labeling index (The percentage of ki67 positive cells) is of low values in benign lesions, but of high values in malignant neoplasms. High labeling index is a very good indicator for high proliferation of cells that indicates malignant nature of such proliferation, and affects the rate of recurrence and outcome [24]

Epithelial membrane antigen (EMA) is one of several glycoproteins found in human milk fat globule membranes which are packaged in the Golgi apparatus, so globular reactivity of the Golgi apparatus may be seen. The glycoprotein identified with EMA is now known to be one of a series of glycoproteins or mucins and is designated MUC1 [25].

Desmin is a protein that is encoded in humans by the DES gene. Desmin is a type III intermediate filament found near the $\mathrm{Z}$ line in sarcomeres. Desmin is only expressed in vertebrates, however homologous proteins are found in many organisms. It is a $52 \mathrm{kD}$ protein that is a subunit of intermediate filaments in skeletal muscle tissue, smooth muscle tissue, and cardiac muscle tissue [5] .

\section{Material and Methods}

This prospective study included 20 cases of non-neoplastic reactive mesothelial proliferations, selected 30 cases of malignant mesothelioma epithelioid type. Pleural effusions were collected from the Chest Department, Benha Faculty of Medicine, Benha University and the International Medical Center (IMC) in the period (June 2015-June 2017). Paraffin-embedded cell blocks of pleural effusion were prepared. The cases of reactive $\mathrm{MH}$ were confirmed with review of the previous and/or current medical records.

The confirmation of MM diagnosis was through IHC stains as caleritin, WT- 1 , CK5/6, TTF- 1 and Leu M 1 . All the patients were associated with clinical and readiological features refaring to MM.

\section{Immunohistochemical staining:}

The cell blocks of the cases were cut $4 \mu \mathrm{m}$ thick, then mounted on positively-charged slides, we 
follow slandered $\mathrm{ABC}$ staining protocol (avidinbiotin complex) that uses the Ultra Vision Detection System (Anti-polyvalent, HRP/DAB, ready-to-use, Lab Vision corporation). For antigen retrieval, microwave treatment in $10 \mathrm{mM}$ citrate buffer (NeoMarkers, Cat. \# AP-9003), pH 6.0 was done and stained with desmin (Dako, Carpentaria, Calif; 1:100 dilution), EMA (Dako; 1:2 dilution), GLUT1 (rabbit polyclonal antibody, Thermo Scientific, Waltham, Mass; 1:200 dilution), p53 (Vector Laboratories, Burlingame, Calif; $1: 30$ dilution), Ki67 proliferation index (Dako, $1: 100$ dilution), and BAP- 1 (clone C-4, cat no sc-28383, Santa Cruz Biotechnology, USA; $1: 100$ dilution) (Table 1). The incubation period was thirty for all IHC stains. The suitable positive and negative controls were used. We apply the freshly prepared DAB-substratechromogen solution as a counterstain.

A single pathologist interpreted both the IHC stains in association with the H\&E stained slides. The pathologist did not know the diagnosis of cases at time of interpretation the IHC stained slides. The atypical mesothelial cells were the target if they can be recognized from the other reactive mesothelial cell, but if such differentiation was difficult; all mesothelial cells were the target.

Table (1): Antibody sources, dilutions, and fixation conditions.

\begin{tabular}{lllll}
\hline Antibody & Source & $\begin{array}{c}\text { Catalogue } \\
\text { No. }\end{array}$ & Dilution & Fixation \\
\hline Desmin & Dako & M0760 & $1: 100$ & $10 \%$ formalin \\
EMA & Dako & N1504 & $1: 2$ & $10 \%$ formalin \\
GLUT-1 & Thermo Scientific & RB9052 & $1: 200$ & $10 \%$ formalin \\
p53 & Vector Laboratories & VPp958 & $1: 30$ & $10 \%$ formalin \\
Ki67 & Dako & M7240 & $1: 100$ & $10 \%$ formalin \\
BAP-1 & Santa Cruz & SC-283 83 & $1: 100$ & $10 \%$ formalin \\
& Biotechnology & & & \\
\hline
\end{tabular}

EMA : Indicates epithelial membrane antigen.

GLUT-1 : Glucose-transport protein 1.

BAP1 : BRCA-1 associated protein.

\section{Interpretation ofIHC staining:}

Desmin immunoreactivity: Recorded as negative when no immunoreactivity was seen, considered as positive if showed strong membranous positivity and cytoplasmic staining. Focal/weak if $<20 \%$ of cells were positive or showed only blush positivity, and positive if strong positivity was seen in $\geq 20 \%$ of cells [26]

EMA and GLUT-1 immunoreactivity: Were recorded as negative (no staining), focal/weak positive if there were a few $(<20 \%)$ scattered cells that showed a membranous staining pattern or if there was only blush cytoplasmic staining but no membranous staining, and positive if there were $20 \%$ of mesothelial cells showed strong membranous accentuation with or without cytoplasmic staining [26].

Ki67: The mesothelial cells that showed positivity were calculated in RMH cases and MM cases. The cases were considered negative if $(0 \%$ of nuclei staining), low $(<10 \%)$, moderate $(10 \%-40 \%)$, and high $(>40 \%)$ [22]

P53: Cases were considered as negative if there was no staining or only faint nuclear staining, focal if there was strong nuclear staining in $<10 \%$ of cells, and positive if the strong nuclear staining was detected in $\geq 10 \%$ of cells [22]

BAP1: The cases were recorded as negative if the nuclear staining was totally absent in all the target cells, associated with positive internal control as lymphocytes or stromal cells in the background. The cases were recorded as positive if at least 5\% of the target cells showed strong nuclear staining. Negative cases in absence of internal positive control were not considered [27]

Data analysis was performed with the statistical package for social sciences (version 16.0.1; SPSS Inc., Chicago, Illinois, USA). Descriptive analysis of the variables and statistical significance of the tests were expressed in $p$-value. $p$-value less than $0.05(<0.05)$ was considered significant and $<0.01$ was highly significant.

\section{Results}

Among the patients with MM, the mean age was 65 years (range, 37-75 years); 20 were men, and 10 were women. Regarding the patients with RMCs, the mean age was 38 years (range, 25-73 years); 16 were men, and 4 were women. The cases were examined histologically and immunohistochemically for EMA, Desmin, P53, Ki67, GLUT1 , and BAP- 1 . The results are shown in Table (2).

To distinguish MM from RMCs, immunohistochemical positivity for P53, GLUT1, EMA, and ki67 had sensitivities of $53 \%, 70 \%, 97 \%$, and $63 \%$ and specificities of $100 \%, 85 \%, 90 \%$, and $70 \%$, respectively, and negativity for BAP-1 and desmin with $63 \%, 80 \%$ sensitivity and $95 \%, 90 \%$ specificity respectively. Immunostaining for detection of GLUT 1, EMA, and was generally concentrated around the cell membrane, with only occasional cytoplasmic staining. Desmin showed cytoplasmic staining in both MM and RMC cases. 

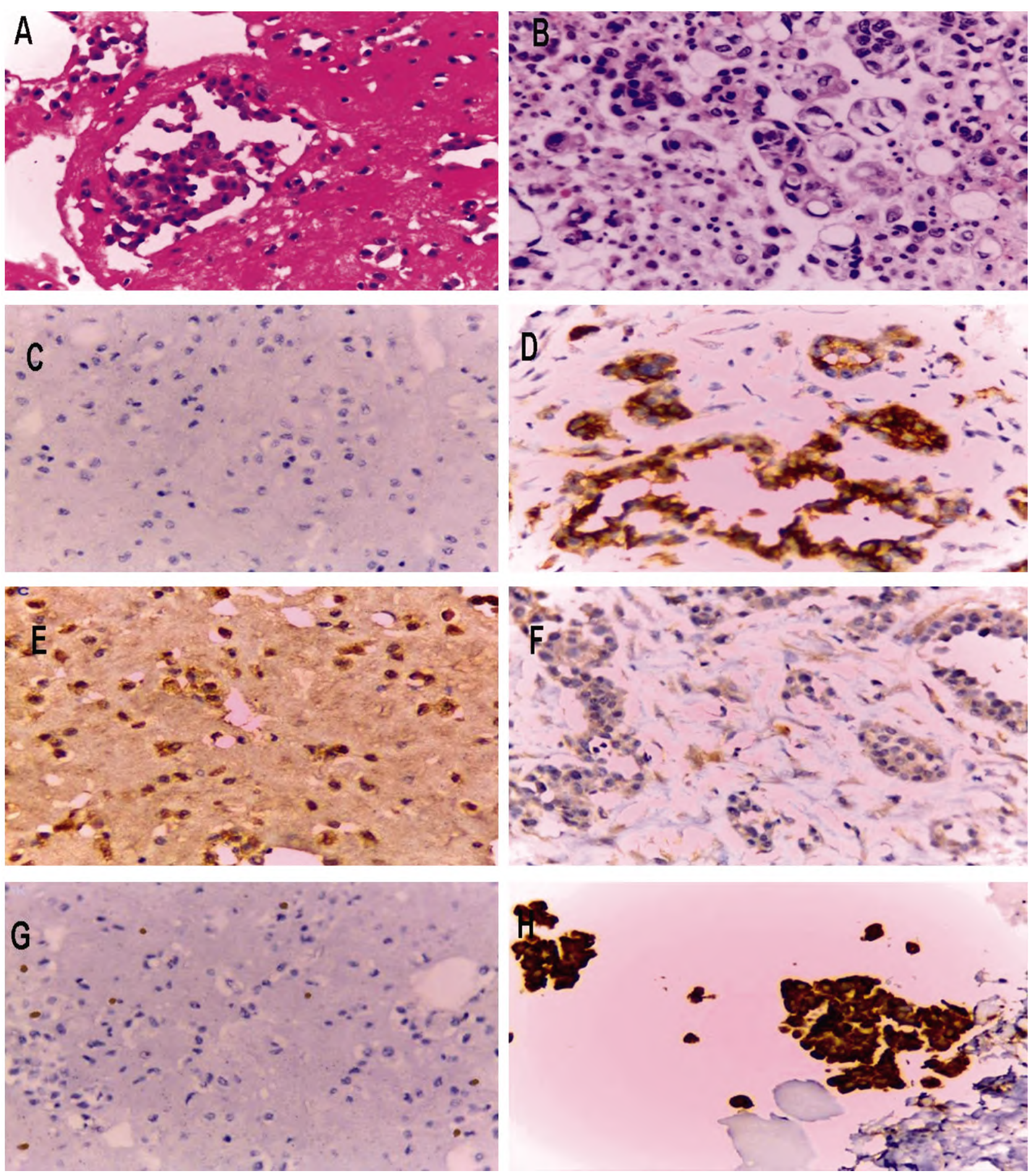

Fig. (1): (A) A case of reactive mesothelial hyperplasia is shown (H \& Ex400). (B) A case of malignant mesothelioma is shown (H \& Ex400). (C) Epithelial membrane antigen (EMA): Reactive mesothelial cells show no immunoreactivity. (D) EMA: Malignant mesothelial cells show positive membranous and cytoplasmic staining. (E) Desmin: Reactive mesothelial cells show strong positive membranous and cytoplasmic staining. (F) Desmin: Malignant mesothelial cells show no to weak and focal staining. (G) GLUT-1: Reactive mesothelial cells show no immunoreactivity, with positive lymphocytes in the background . (H) GLUT-1: Malignant mesothelial cells show strong membranous positivity with some cytoplasmic staining (IHC, DAB x 400). 

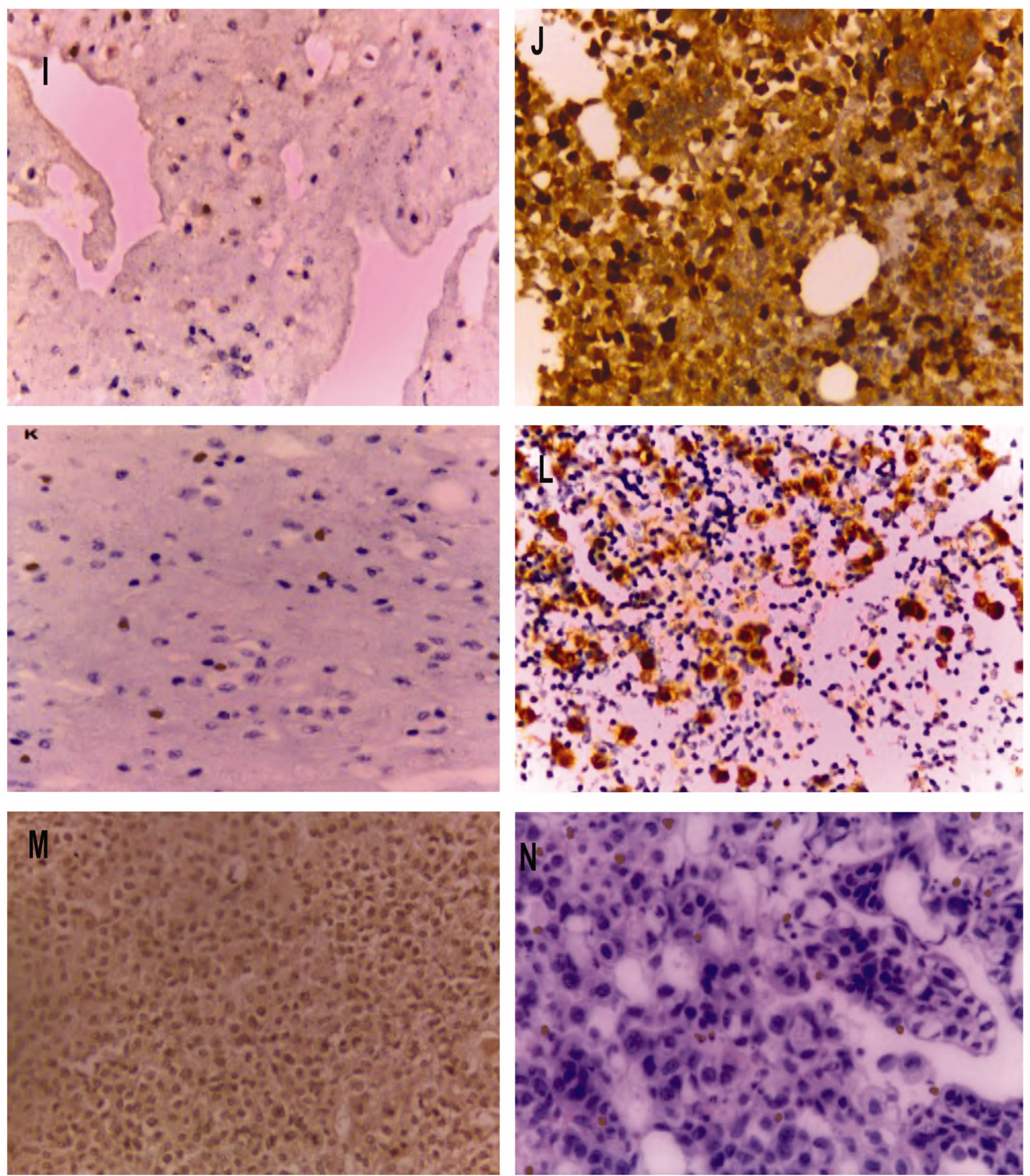

Fig. (2): (I) P53: Reactive mesothelial cells show no immunoreactivity. (J) P53: Malignant mesothelial cells show strong nuclear staining in $>10 \%$ of cells. (K) Ki67: Reactive mesothelial cells showed low nucler staining $(<10 \%)(\mathrm{L})$ Ki67: Malignant mesothelial cells showed high nucler staining (>40\%). (M) BRCA-1 associated protein-1 (BAP-1): Reactive mesothelial cells showed positive nuclear staining in target cells. (N) BAP-1: Malignant mesothelial cells showed absent nuclear staining in the target cells in the presence of a positive internal control, provided by lymphocytes (IHC, DAB x400). 
Table (2): Summary of results of immunohistochemical stains.

\begin{tabular}{|c|c|c|c|c|c|c|c|}
\hline \multirow{2}{*}{ Stain } & \multicolumn{2}{|c|}{ Mesotheliom } & \multicolumn{2}{|c|}{ Reactive } & \multirow{2}{*}{ Sensitivity } & \multirow{2}{*}{ Specificity } & \multirow{2}{*}{$p$-value } \\
\hline & No. & $\%$ & No. & $\%$ & & & \\
\hline \multicolumn{8}{|l|}{$B A P-1:$} \\
\hline Negative & 19 & 63.3 & 1 & 5 & $63 \%$ & $95 \%$ & $<.005$ \\
\hline Positive & 11 & 36.7 & 19 & 95 & & & \\
\hline Total & 30 & & 20 & & & & \\
\hline \multicolumn{8}{|l|}{ GLUT-1: } \\
\hline Negative to focal $<20 \%$ & 9 & 30 & 17 & 85 & $70 \%$ & $85 \%$ & $<.005$ \\
\hline Positive ( $\geq 20 \%)$ & 21 & 70 & 3 & 15 & & & \\
\hline Total & 30 & & 20 & & & & \\
\hline \multicolumn{8}{|l|}{ Desmin: } \\
\hline Negative & 22 & 73.3 & 3 & 15 & $80 \%$ & $90 \%$ & $<.001$ \\
\hline Focal $(<20 \%)$ & 5 & 16.7 & 1 & 5 & & & \\
\hline Positive ( $\geq 20 \%$ ) & 3 & 10 & 16 & 80 & & & \\
\hline Total & 30 & & 20 & & & & \\
\hline \multicolumn{8}{|l|}{ EMA: } \\
\hline Negative & 0 & 0 & 14 & 70 & $97 \%$ & $90 \%$ & $<.001$ \\
\hline Focal $(<20 \%)$ or weak & 1 & 3.3 & 4 & 20 & & & \\
\hline Positive $(\geq 20 \%)$ & 29 & 96.7 & 2 & 10 & & & \\
\hline Total & 30 & & 20 & & & & \\
\hline \multicolumn{8}{|l|}{ P53: } \\
\hline Negative to focal $(<10 \%)$ & 14 & 46.7 & 19 & 95 & $53 \%$ & $100 \%$ & $<.001$ \\
\hline Positive & 16 & 53.3 & 1 & 5 & & & \\
\hline Total & 30 & & 20 & & & & \\
\hline \multicolumn{7}{|l|}{ Ki67 proliferative: } & 0.040 \\
\hline Negative to low $(<10 \%)$ & 11 & 36.6 & 14 & 70 & $63 \%$ & $70 \%$ & \\
\hline Moderate $(10 \%-39 \%)$ & 14 & 46.7 & 4 & 20 & $17 \%$ & $90 \%$ & \\
\hline High $(>40 \%)$ & 5 & 16.7 & 2 & 10 & & & \\
\hline Total & 30 & & 20 & & & & \\
\hline
\end{tabular}

\section{Discussion}

Discrimination between malignant mesothelioma of the pleura from reactive proliferation of mesothelial cells is still a big challenge. Most cases of MM present with pleural effusion, and the diagnosis of mesothelioma in such effusion is not an easy task for the pathologist, even the experts. It is essential to differentiate MM from reactive proliferation of mesothelial cells, as the later is non-neoplastic lesion that may associate many other conditions as pleuritis, peritonitis, serosal invasion of other cancers. There is a great resemblance of MM to RMH, so it is difficult to differentiate between them by routine histological examination alone. Many novel IHC markers have been used to differentiate between MM from other non-serosal malignancies and RMH.

BRCA1-associated protein 1 (BAP1) is a tumour suppressor gene frequently inactivated in mesothelioma. In the present study, out of 30 cases of MM, 19 cases $(63.3 \%)$ showed loss of expression of BAP-1, however only one case $(5 \%)$ of RMH showed loss of expression of BAP-1. These results were in agreement to Andrici et al., [27]. That revealed BAP-1 loss in 57\% of cases of MM, also Righi et al., [28] found negative nuclear staining for BAP1 occurred in $62 \%$ of MPMs (including
$27 \%$ with a cytoplasmic pattern). Hida et al., [29] reported that immunohistochemical detection of loss of BRCA1 associated protein 1 (BAP1) is a reliable markers for MPM diagnosis. Kushitanii et al., [24] reported that BAP1 had $66.2 \%$ sensitivity and $100 \%$ specificity for the differentiation of MM from RMH. Cozzi et al, [30] found that in malignant mesothelioma cases, there was absent nuclear staining of BAP $176.5 \%$ of the cytologic effusion and $47.5 \%$ of the tissue biopsies but all cases of reactive mesothelial hyperplasia showed nuclear expression for BAP1. Also he concluded that cases with absent expression of BAP1 IHC is strongly supported to be malignant mesothelioma. BAP1 may be used as one of the IHC panels for diagnosis of MM in cytologic effusion with high specificity and sensitivity.

In the present research, we found that $70 \%$ of MM cases showed positive expression of GLUT1 , however among the RMH cases, $15 \%$ of cases showed positive expression of GLUT-1. These results were supported by Minato et al., [20] who found that the sensitivity of GLUT-1 was $85 \%$. Also, Kato et al., [31] found that Immunohistochemical GLUT-1 expression was seen in $(100 \%)$ of MMs cases and in $100 \%$ of cases showed linear membranous staining \pm cytoplasmic staining. Con- 
versely, all cases of reactive mesothelial proliferation showed negative expression for GLUT-1, concluding that GLUT-1 may be used as an IHC marker, with high sensitivity and specificity for differentiation between reactive mesothelilal hyperplasia and malignant mesothelioma cases. Similarly, Mog et al., [19] concluded that mestoelioma cases showed more levels of IHC expression of GLUT-1 than RMH. Also, found that higher levels ofGLUT-1, mRNA in mesothelioma cases than in non-neoplastic mesothelial cell lines. Conversely, Chang et al., [32] reported that the sensitivity for GLUT-1 was 29\%. Hasteh et al., [26] documented $47 \%$ sensitivity of GLUT-1 in his study, and that $12 \%$ of benign cases showed positive staining for GLUT-1. Also, Stephen et al., [33] reported that The sensitivity of GLUT-1 in epithelioid malignant mesothelioma was $49 \%$.

As regard Desmin staining, $80 \%$ of $\mathrm{RMH}$ showed positive staining, however only $10 \%$ of MM cases showed positive staining, and this difference was statistically significant $(p$-value $<.001)$. Concerning EMA staining, 10\% of RMH cases showed positive staining, however nearly all cases (97\%) showed positive staining of it. These results were in agreement to our results in a previous study done on tissue biopsy for differentiation between reactive and malignant mesothelial proliferation [25] as $88.2 \%$ of RMH cases (15 of 17), and $7.7 \%$ of MM cases (1 case of 13 cases) showed positive expression of Desmin. However as regard the EMA staining results, $5.9 \%$ of RMH (1 case of 13 case), and $92.3 \%$ of MM cases (12 of 13) showed positive expression. Also Minato et al., [20] reported EMA as a positive marker for MM cases. Chang et al., [32]. Found that the sensitivity of EMA was $46 \%$ and $100 \%$ specificity in differentiation between RMH and MM cases. In a study of Hasteh et al., [26] it was found that 9\% (6 of 64) of benign cases showed positivity for EMA, but all the malignant cases $100 \%$ (52 of 52) showed such EMA positivity $(p<.001)$. Arslan et al., [34] found in his study on tissue biopsy that staining with EMA was observed in $68.7 \%$ of cases ( 45 of 67 ), whereas weak positivity was detected in only one case with RMH, and this study concluded that EMA has an important role in differentiation between reactive and malignant mesothelila proliferation. Conversely, Salman et al., [35] reported in his study a case of primary $\mathrm{MM}$ of the peritoneum that showed positivity for desmin and negative expression of EMA.

The great conflict in the results may be explained by many causes, as specimen of different types, different patient population or scoring systems. Also, antibodies used mono or polyclonal, the antigen retrieval methods, the histologic type of MM used may also affect the results.

As regard p53 immunostaining, it was found that strong nuclear positivity was detected in 5\% of RMH cases ( 1 of 20), however in MM cases, $53 \%$ (16 of 30) of cases showed strong positive nuclear staining, and that difference was statistically significant ( $p$-value $<0.05$ ). Our results matched to results reported by Hasteh et al., [26] who found strong nuclear expression of P53 was found in $2 \%$ (1 of 46) of RMH and 47\% (7 of 15) of MM cases $(p<.001)$. Also, Hafez and Tahoun, [22] reported that positive nuclear expression for $\mathrm{p} 53$ was found in 31 out of $41 \mathrm{MM}$ cases $(75.6 \%)$ and in 3 out of 50 RMH cases $(6 \%), p<0.005$. p53 had $75.6 \%$ sensitivity, $94 \%$ specificity. Conversely, Koo et al., [21] concluded that there was no great difference in the extent of nuclear expression of P53 between RMH and MM cases.

Ki67 IHC staining in this study revealed that Ki67 showed strong nuclear expression in $>40 \%$ of mesothelial cells in 10\% ( 2 of 20) of RMH and $16.6 \%$ (5 of 30) of MM cases ( $p=.38$ ). Similarly, Hasteh et al., [26] who found that Ki67 showed strong nuclear positivity in $>40 \%$ of mesothelial cells in 9\% (6 of 64) of benign and 16\% (8 of 49) of malignant cases $(p=.38)$. These results were conflicting to results reported by Hafez and Tahoun, [22] who found that ki67 immunostaining was positive in 30 out of 41 malignant effusions $(73.2 \%)$ and in 17 out of 50 benign effusions (34\%), $p<0.05$. ki67 had $73.2 \%$ sensitivity, $66 \%$ specificity. Kushitani et al., [24] concluded that Ki-67 (cut-off value: $10 \%$ ) had $85.1 \%$ sensitivity and $87.5 \%$ specificity in differentiation between reactive and malignant mesothelial proliferation.

Disclosures: No relevant conflicts of interest to declare.

\section{References}

1- BENJAMIN M. ROBINSON: Malignant pleural mesothelioma: An epidemiological perspective. Ann. Cardiothorac. Surg. Nov., 1 (4): 491-496, 2012.

2- ANNA C. BIBBY, DUNEESHA De FONSEKA, et al.: Exploring the characteristics of patients with mesothelioma who chose active symptom control over chemotherapy as first-line treatment: A prospective, observational, single centre study. BMC Palliat Care, 16: 71, 2017.

3- KLAMPATSA A., ANDREW R. HAAS, EDMUND K. and ALBELDA S.M.: Chimeric Antigen Receptor (CAR) T Cell Therapy for Malignant Pleural Mesothelioma (MPM). Cancers (Basel). Sep., 9 (9): 115, 2017.

4- CASJENS S., DANIEL G., JOHNEN G., WEBER D.G., RAIKO I., TAEGER D., et al.: Assessment of potential predictors of calretinin and mesothelin to improve the 
diagnostic performance to detect malignant mesothelioma results from a population-based cohort study. BMJ Open, 7 (10): e017104, 2017.

5- Churg A., M.D. and Galataeu Salle F.G.: The Separation of Benign and Malignant Mesothelial Proliferations. Arch. Pathol. Lab. Med., Vol 136, October 2012.

6- BETTA P.G., MAGNANI C., BENSI T., TRINCHERI N.F. and ORECCHIA S.: Immunohistochemistry and Molecular Diagnostics of Pleural Malignant Mesothelioma. Arch. Pathol. Lab. Med., 136: 253-261, 2012.

7- CHURG A., SHEFFIELD B.S. and GALATEAU-SALLE F.1.: New Markers for Separating Benign From Malignant Mesothelial Proliferations: Are We There Yet? Arch. Pathol. Lab. Med. Apr., 140 (4): 318-21, 2016.

8- BONELLI M.A., FUMAROLA C., La MONICA S., ALFIERI R.: New therapeutic strategies for malignant pleural mesothelioma. Biochem. Pharmacol. Jan., 1: 123: 8-18, 2017.

9- ORDÓÑEZ N.G.: The immunohistochemical diagnosis of mesothelioma: A comparative study of epithelioid mesothelioma and lung adenocarcinoma. Am. J. Surg. Pathol. Aug., 27 (8): 1031-51, 2003.

10- BRUNO R.1, ALÌ G.2 and FONTANINI G.1,3: Molecular markers and new diagnostic methods to differentiate malignant from benign mesothelial pleural proliferations: A literature review. J Thorac Dis. Jan., 10 (Suppl 2): S342-S352, 2018.

11- KIMBERLY A. BIRNIE1, CECILIA M. PRÊLE1,2, PHILIP J. THOMPSON1, BAHAREH BADRIAN1 and STEVEN E. MUTSAERS: Targeting microRNA to improve diagnostic and therapeutic approaches for malignant mesothelioma. Oncotarget. Sep., 29; 8 (44): 78193-78207, 2017.

12- KINOSHITA Y1, HIDA T., HAMASAKI M., MATSUMOTO S., SATO A., TSUJIMURA, et al: combination of MTAP and BAP 1 immunohistochemistry in pleural effusion cytology for the diagnosis of mesothelioma. Cancer Cytopathol. Jan., 126 (1): 54-63, 2018.

13- WANG L.M., SHI Z.W., WANG J.L., LV Z., DU F.B., YANG Q.B. and WANG Y.: Diagnostic accuracy of BRCA1-associated protein 1 in malignant mesothelioma: A meta-analysis. Oncotarget. Aug., 17; 8 (40): 6886368872, 2017.

14- PULFORD E., HUILGO K., MOFFAT D., DOUGLAS W. HENDERSON, and SONJA KLEBE: Malignant Mesothelioma, BAP1 Immunohistochemistry, and VEGFA: Does BAP1 Have Potential for Early Diagnosis and Assessment of Prognosis? Dis. Markers, 2017: 1310478, 2017.

15- HWANG H.C., SHEFFIELD B.S., RODRIGUEZ S., THOMPSON K., THOMPSON K., TSE C.H., GOWN A.M., CHURG A., et al.: Utility of BAP 1 Immunohistochemistry and p16 (CDKN2A) FISH in the Diagnosis of Malignant Mesothelioma in Effusion Cytology Specimens. Am. J. Surg. Pathol. Jan., 40 (1): 120-6, 2016.

16- WU D., HIROSHIMA K., YUSA T. and OZAKI D. Usefulness of p16/CDKN2A fluorescence in situ hybridization and BAP1 immunohistochemistry for the diagnosis of biphasic mesothelioma. Ann. Diagn. Pathol. Feb., 26: 31-37, 2017.
17- CIGOGNETTI M1, LONARDI S1, FISOGNI S1, BALZARINI P., PELLEGRINI V., TIRONI A., et al.: BAP1 (BRCA1-associated protein 1) is a highly specific marker for differentiating mesothelioma from reactive mesothelial proliferations. Mod. Pathol. Aug., 28 (8): 1043-57, 2015.

18- McGREGOR S.M., McELHERNE J., MINOR A., KELLER-RAMEY J4, DUNNING R5, HUSAIN A.N., et al.: BAP 1 immunohistochemistry has limited prognostic utility as a complement of CDKN2A (p16) fluorescence in situ hybridization in malignant pleural mesothelioma. Hum. Pathol. Feb., 60: 86-94, 2017.

19-MOGI A., KOGA K., AOKI M., HAMASAKI M., UESUGI N., IWASAKI A., et al.: Expression and role of GLUT1, MCT-1, and MCT-4 in malignant pleural mesothelioma. Virchows Archiv. January, Volume 462, Issue 1, pp 8393, 2013.

20- MINATO H1, KUROSE N., FUKUSHIMA M., NOJIMA T., USUDA K., SAGAWA M., et al.: Comparative immunohistochemical analysis of IMP3, GLUT1, EMA, CD146, and desmin for distinguishing malignant mesothelioma from reactive mesothelial cells. Am. J. Clin. Pathol. Jan., 141 (1): 85-93, 2014.

21- KOO S.M., SOO-TAEK UH, DONG WON KIM, KIM KU1 and KIM Y.K.: p53 Expression in a Malignant Mesothelioma Patient during Seven-Year Follow-up. Tuberc Respir Dis (Seoul). Jun., 76(6): 284-288, 2014.

22- HAFEZ N.H. and TAHOUN N.S.: Diagnostic value of p53 and ki67 immunostaining for distinguishing benign from malignant serous effusions. J. ENCI, Volume 23, Issue 4, December, Pages 155-162, 2011.

23- PILLAI K., POURGHOLAMI M.H., CHUA T.C. and MORRIS D.L.: Ki67-BCL2 index in prognosis of malignant peritoneal mesothelioma. Am. J. Cancer Res., 3 (4): 411-423, 2013.

24- KUSHITANII K., AMATYAI V.J., MAWASA S., SUZUKI R1, MIYATA Y3, OKADA M., et al.: Utility of Survivin, BAP 1, and Ki 67 immunohistochemistry in distinguishing epithelioid mesothelioma from reactive mesothelial hyperplasia. Oncology Letters, 15: 35403547, 2018.

25- AL MEHY G.F., ABD EL FATTAH G.A., GOUDA M.H., ELSAWY R.M. and AMER M.M.: Combined serum and immunohistochemical differentiation between reactive, and malignant mesothelial proliferations. Egypt J. Chest Dis. Tuberc., 2015.

26- HASTEH F1, LIN G.Y., WEIDNER N. and MICHAEL C.W.: The use of immunohistochemistry to distinguish reactive mesothelial cells from malignant mesothelioma in cytologic effusions. Cancer Cytopathol. Apr., 25; 118 (2): 90-6, 2010

27- ANDRICI J., SHEEN A., SIOSON L., WARDELL K2, CLARKSON A., WATSON N., et al.: Loss of expression of BAP 1 is a useful adjunct, which strongly supports the diagnosis of mesothelioma in effusion cytology. Modern Pathology, 28: 1360-1368, 2015.

28- RIGHI L., DUREGON E., VATRANO S., IZZO S., GIORCELLI J., RONDÓN-LAGOS M., et al.: BRCA1Associated Protein 1 (BAP1) Immunohistochemical Expression as a Diagnostic Tool in Malignant Pleural Mesothelioma Classification: A Large Retrospective Study. J. Thorac. Oncol. Nov., 11 (11): 2006-2017, 2016. 
29- HIDA T., HAMASAKI M., MATSUMOTO S., SATO A., TSUJIMURA T., et al.: Immunohistochemical detection of MTAP and BAP 1 protein loss for mesothelioma diagnosis: Comparison with 9p21 FISH and BAP1 immunohistochemistry. Lung cancer, Volume 104, February, Pages 98-105, 2017.

30- COZZI I1, OPRESCU FA1, RULLO E1 and ASCOLI V1.: Loss of BRCA1-associated protein 1 (BAP1) expression is useful in diagnostic cytopathology of malignant mesothelioma in effusions. Diagn Cytopathol. Jan., 46 (1): 9-14, 2018.

31- KATO Y1, TSUTA K., SEKI K., MAESHIMA A.M., WATANABE S., SUZUKI K., ASAMURA H., MATSUNO Y., et al.: Immunohistochemical detection of GLUT1 can discriminate between reactive mesothelium and malignant mesothelioma. Mod. Pathol. Feb., 20 (2): 21520. Epub 2006 Dec 22, 2007.

32- CHANG S1, OH M.H., JI S.Y., HAN J., KIM T.J., EOM M., et al.: Practical utility of insulin-like growth factor
II mRNA-binding protein 3, glucose transporter 1, and epithelial membrane antigen for distinguishing malignant mesotheliomas from benign mesothelial proliferations. Pathol. Int. Dec., 64 (12): 607-12, 2014.

33- STEPHEN M. LAGANA, ROBERT N., et al.: Utility of Glucose Transporter 1 in the Distinction of Benign and Malignant Thoracic and Abdominal Mesothelial Lesions. Arch. Pathol. Lab. Med., Vol. 136, July, 2012.

34- ARSLAN S., BAK1R K. and ELBEYLI L.: Epithelial membrane antigen in differential diagnosis of malignant mesothelioma, metastatic adenocarcinoma, and reactive mesothelial hyperplasia. Turk Gogus Kalp Dama, 24 (1): 108-112, 2016.

35- SALMAN W.D., EYDEN B., SHELTON D., HOWAT A., AL-DAWOUD A. and TWAIJ Z.: An EMA negative, desmin positive malignant mesothelioma: limitations of immunohistochemistry? J. Clin. Pathol. Jul., 62 (7): 651$2,2009$.

\section{التمايز المناعى الكيميائى بين التكاثرات الظهارية

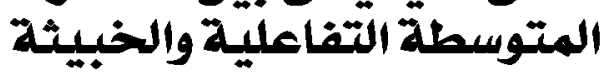

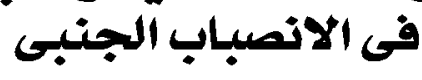

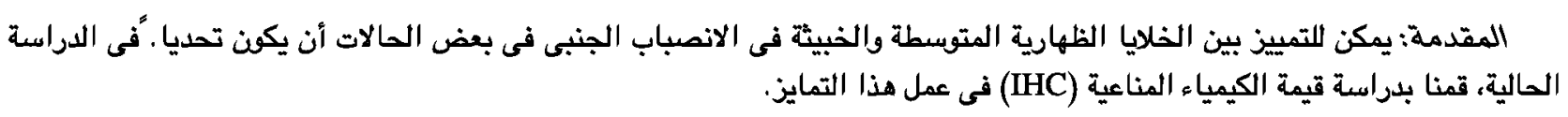

طرق البحث: تم اختيار السوائل الجنبية من • ب حالة تم تشخيصها على أنها ودم الظهارة المتوبسطة الضييثة (MM) ونوع الظهارة الضبيثة

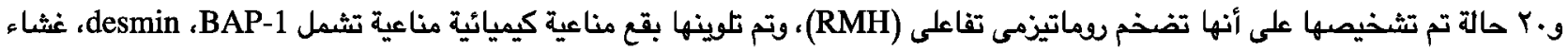

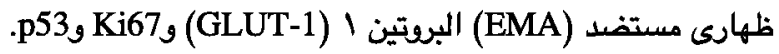

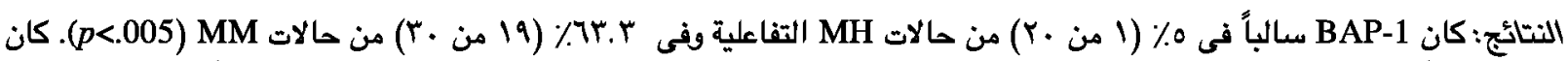

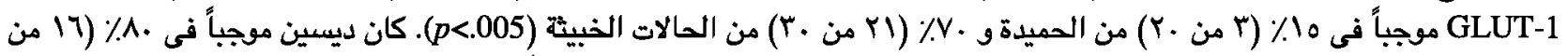

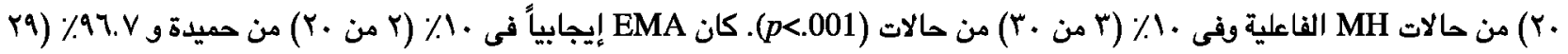

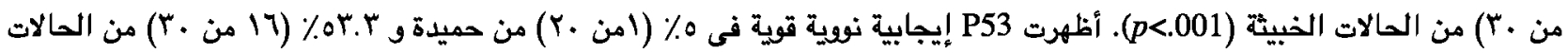

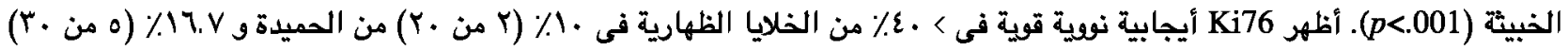

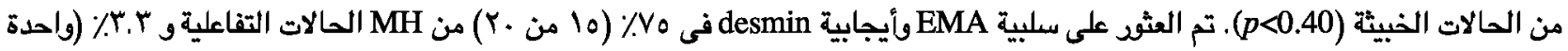

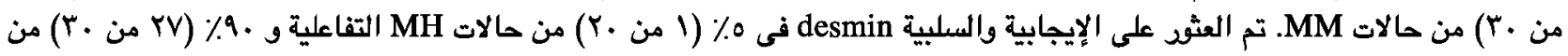

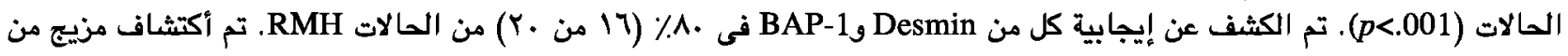
BAP-1و Desmin

الخلاصة: أظهرت الحالات الإيجابية لـ EMA والسلبية لـ desmin تؤيد بشدة ودم الظهارة المتوسطة الخبيثة. على العكس من ذلك، أظهرت

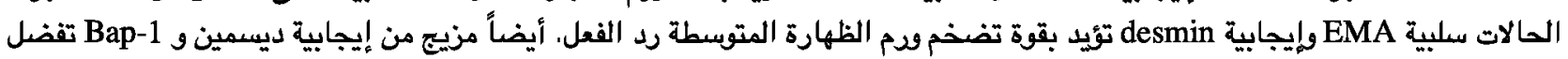

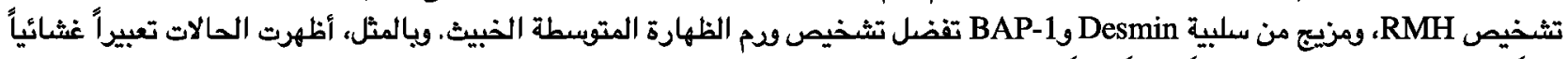

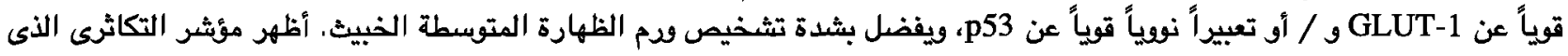
أكتشفه Ki76 عدم وجود فرق كبير بين الحالات التفاعلية والخبيثة. 